\title{
EAl Endorsed Transactions

\section{Spatiotemporal Variability of Air Quality Time Series for developing countries: Case of Ho Chi Minh city, Vietnam}

\author{
Hue Nam K. Nguyen ${ }^{1}$, Nam Hung N. Tran ${ }^{1}$, Bac T. Vu${ }^{1}$, Bang Q. Ho ${ }^{2}$ \\ ${ }^{1}$ High School For the Gifted, Vietnam National University in Ho Chi Minh City, Vietnam \\ 153 Nguyen Chi Thanh street, District 10, Ho Chi Minh city \\ Email:nguyenkimhuenamtdn@gmail.com,nguyennamtranhung1303@gmail.com,vtbac2013@gmail.com \\ ${ }^{2}$ Institute of Environment and Resources, Vietnam National University in Ho Chi Minh City, Vietnam \\ 142 To Hien Thanh Street, Ward 14. District 10, Ho Chi Minh city \\ Email: bangquoc@yahoo.com
}

\section{Abstract}

In the recent years, air pollution has become a severe problem not only for Vietnam, but also for other countries. Ho Chi Minh City (HCMC) is the largest city in Vietnam where many air pollutants exceeded the Vietnam national technical regulation in ambient air quality including $\mathrm{PM}_{2.5}, \mathrm{NO}_{\mathrm{x}}$, Ozone and $\mathrm{CO}$. These high pollutant concentrations have destroyed human health of people in Ho Chi Minh City. This research is aimed to (i) analyse and assess the change in spatiotemporal of the air polluted substances in Ho Chi Minh City; (ii) study the impact of weather patern to air pollutants dispersion over Ho Chi Minh City. The description statistical method is applied to evaluate the air quality in every monitoring location during the period 2005 to 2016, and the Inverse Distance Weighting (IDW) spatial interpolation from Geographical Information Systems (GIS) was applied to create a map of polluted substances in air quality, especially Total Suspended Particles (TSP), Nitrogen oxides $\left(\mathrm{NO}_{\mathrm{x}}\right)$, Lead $(\mathrm{Pb})$ and Carbon monoxide $(\mathrm{CO})$, of the change in concentration of the polluted substances for every pixel in all researched locations. IDW method was validated by comparing between air quality monitoring and IDW spatial interpolation method. The results shown that IDW method is qualify for this study with $\mathrm{R}^{2}=$ 0.93 and $d=0.74$ at Dinh Tien Hoang - Dien Bien Phu, An Suong and Go Vap monitoring locations. The IDW interpolation method was also good result for $\mathrm{NO}_{\mathrm{x}}$ with $\mathrm{R}^{2}=0.96$ and $\mathrm{d}=0.75$ at the Hang Xanh, An Suong, and Huynh Tan Phat monitoring locations. The results shown that the highest $\mathrm{CO}$ concentration is in Go Vap district, with the average is 14.849 $\mathrm{mg} / \mathrm{m}^{3}$, TSP is highest in An Suong area with the average is $0.687 \mathrm{mg} / \mathrm{m}^{3} . \mathrm{NO}_{\mathrm{x}}$ is highest in Dien Bien Phu wih $0.199 \mathrm{mg} / \mathrm{m}^{3}$. The spatial of air quality shown that the spread continues towards the north, northwest, and northeast direction of Ho Chi Minh City because the main air emission sources are in the center of HCMC and the main wind direction is south, southeast and northeast. The wind direction blows air pollutants from center of city toward to the north, northwest, and northeast of Ho Chi Minh City. The results of study also shown that the relations between policy and air pollution level. Policy interventions on air quality management will have a major impact on reducing air pollution for HCMC, such as policies that tighten vehicle exhaust emissions (from EURO II standard to EURO VI standard) and policy on cleaner fuel.

Keywords: Air Pollution, Spatial Interpolation Method, IDW, Ho Chi Minh city.

Received on 31 March 2020, accepted on 15 May 2020, published on 18 May 2020

Copyright (C) 2020 Hue Nam K. Nguyen et al., licensed to EAI. This is an open access article distributed under the terms of the Creative Commons Attribution licence (http://creativecommons.org/licenses/by/3.0/), which permits unlimited use, distribution and reproduction in any medium so long as the original work is properly cited.

doi: 10.4108/eai.18-5-2020.164585

"Corresponding author. Email: bangquoc@yahoo.com, vtbac2013@gmail.com 


\section{Introduction}

Ho Chi Minh City (HCMC) is considered to be the largest city in Vietnam due to its population and ecomony. In the recent years, as the population and the traffic congestion continues to increase rapidly, the air quality in HCMC has become one of the main concerns for the local authority. The city population, estimated in 2018 , is nearly 10 million official residents, and this number does not count people from other provinces coming to to HCMC searching for jobs [1]. Every year, the population increases by 3 hundred thousand people, and this poses a great challenge for the environment in HCMC, in general, and the transportation infrastructure, in particular. Recent studies show that HCMC has over 8.5 million motorbikes with $5.4 \%$ increase rate, and nearly 508 thousand cars with $14.5 \%$ annual increase rate. Seriously, there are 19 , it is estimated more than 1 million bikes are used in HCMC [1]. In addition, there are 19 manufacturing and industrial zones, 30 industrial clusters on an area of 1,900 ha, and numerous factories and enterprises located separately HCMC [1].

The components of total transportation in HCMC includes: $3.7 \%$ for public transport, $96.3 \%$ left are for private vehicles [2], which consist mainly of motorbikes as aforementioned. The recent study shown that the relationship between air pollution and human health, an estimated $90 \%$ of children less than 5 years old in HCMC suffer from respiratory diseases [3]. Furthermore, according to the World Economic Forum in 2012, Vietnam is one of the top - ten countries affected the worst air pollution in the world [4]. It is clear that in urban areas such as HCMC, traffic contributes directly to air pollution [5].

As reported by World Health Organization (WHO) [6], the air pollution due to emission from traffic activities is severe, especially the fine particle $\mathrm{PM}_{2.5}$. This particle is the main cause for respiratory problems, lung cancer, and mortality. In a recent study, it is shown that $\mathrm{PM}_{2.5}$ concentration in HCMC (129 micrograms $\left./ \mathrm{m}^{3}\right)$ is 3.5 times higher than the Vietnam national technical regulation for ambient air (QCVN 05:2013, namely QCVN). In addition $\mathrm{PM}_{2.5}, \mathrm{CO}$, Ozone and $\mathrm{NO}_{2}$ concentration in $\mathrm{HCMC}$ is also many times higher than Vietnam national technical regulation for ambient air. For instance, from January to March in 2016, the average of NO2 concentration varied from 0.16 to $0.27 \mathrm{mg} / \mathrm{m}^{3}$, and $51 \%$ of the monitoring values are higher than QCVN. Severely, at the An Suong monitoring station, it is reported than $76 \% \quad \mathrm{NO}_{2}$ concentration value is higher than QCVN, particularly some monitoring values up to $0.66 \mathrm{mg} / \mathrm{m}^{3}$ (exceeding QCVN 3.32 times) [7].

The $\mathrm{PM}_{10}$ is also reported to cause extreme severe impacts on human health due to its concentration, which is usually higher than QCVN. Data also shows that ozone concentration in HCMC also exceeded the QCVN almost 2 times. The International Agency for Research on Cancer (IARC) in 2012 has classified diesel engine emission as Carcinogenic to Humans. IARC also noted that emissions from diesel engines were one of the main causes for lung and bladder cancer [6]. Moreover, we have substantial and sufficient evidence that shows serious impacts of pollution on human health and HCMC air quality has become polluted.

To reduce the air pollution, HCMC's local authorities need more efforts to study about air qualities for developing strategies. Firstly, they need to know clearly the air pollutants distribution over HCMC. Then, they will develop abatement measures for reducing air pollution. However, until now, HCMC government does not have any automatically air quality monitoring stations. They do not have air quality information over HCMC. They have only 15 manual (collect air samples by manual pump and paper filter, then bring the samples to laboratory to analyse the samples) air quality stations. Therefore, In this study, the air pollutants in air quality such as TSP, $\mathrm{NO}_{\mathrm{x}}, \mathrm{Pb}$ and $\mathrm{CO}$ was assessed in terms of space and time during the period of 2005 to 2016 in Ho Chi Minh city.

\section{Study Area}

The selected study area is HCMC, which is located in the southeast region of Vietnam. The city lies approximately between $10^{\circ} 20^{\prime}-11^{0} 10^{\prime} \mathrm{N}$ in latitude and $106^{\circ} 20^{\prime}-$ $107^{\circ} 05^{\prime} \mathrm{E}$ in longitude. HCMC consists of 24 different districts, which make up total estimated $2,095 \mathrm{~km}^{2}$. According to a report by Asian Development Bank the majority of HCMC areas are low - lying areas; the elevations of $0-1$ and $1-2$ meters are responsible for approximately $40-45 \%$ and $15-20 \%$ total metropolitan areas, respectively [8].

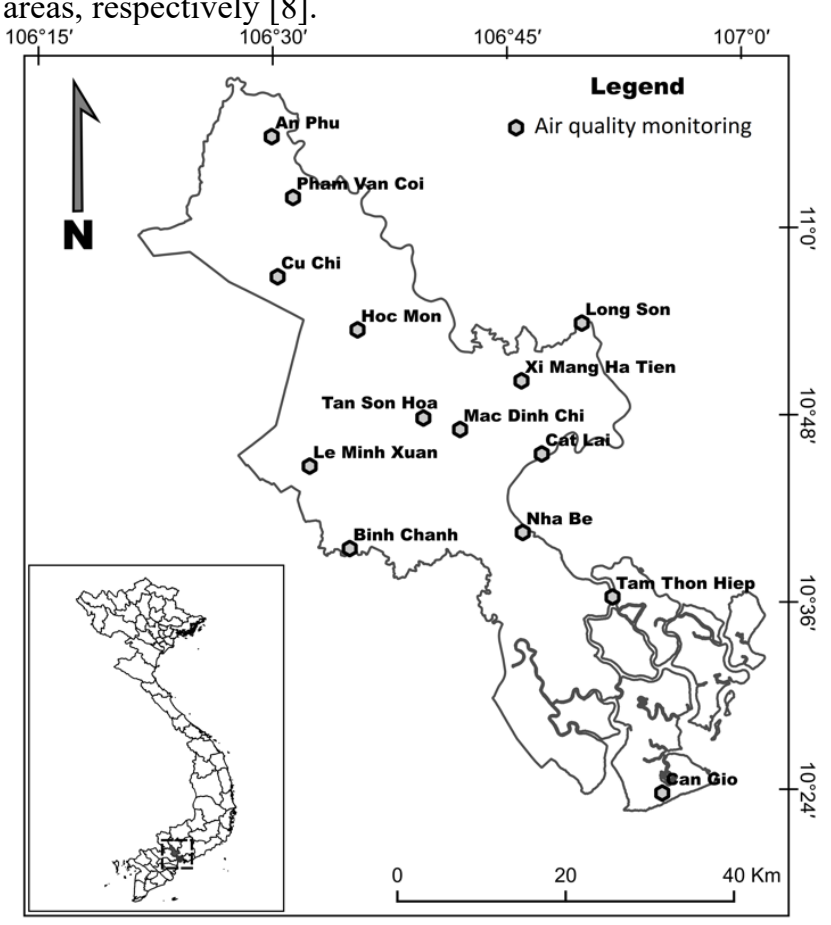

Figure 1. Geographical location and spatial distribution of 15 Manual Air Quality Monitoring stations in HCMC 


\section{Methods}

Figure 2 shows a brief description of the schematic framework of research methodology. The air polluted substances including TSP, $\mathrm{NO}_{x}, \mathrm{CO}$ and $\mathrm{Pb}$ data were collected and calculated. The descriptive statistic method and spatial interpolation approach were applied to analyze and examine temporal air pollution trends TSP, $\mathrm{NO}_{\mathrm{x}}, \mathrm{CO}$ and $\mathrm{Pb}$ for the period 2005-2016. The air polluted substances values were further used for the interpolating procedure for comparative spatial assessment. Inverse distance weighting (IDW) algorithm was applied in this study as spatial interpolation techniques with ArcGIS software [9].

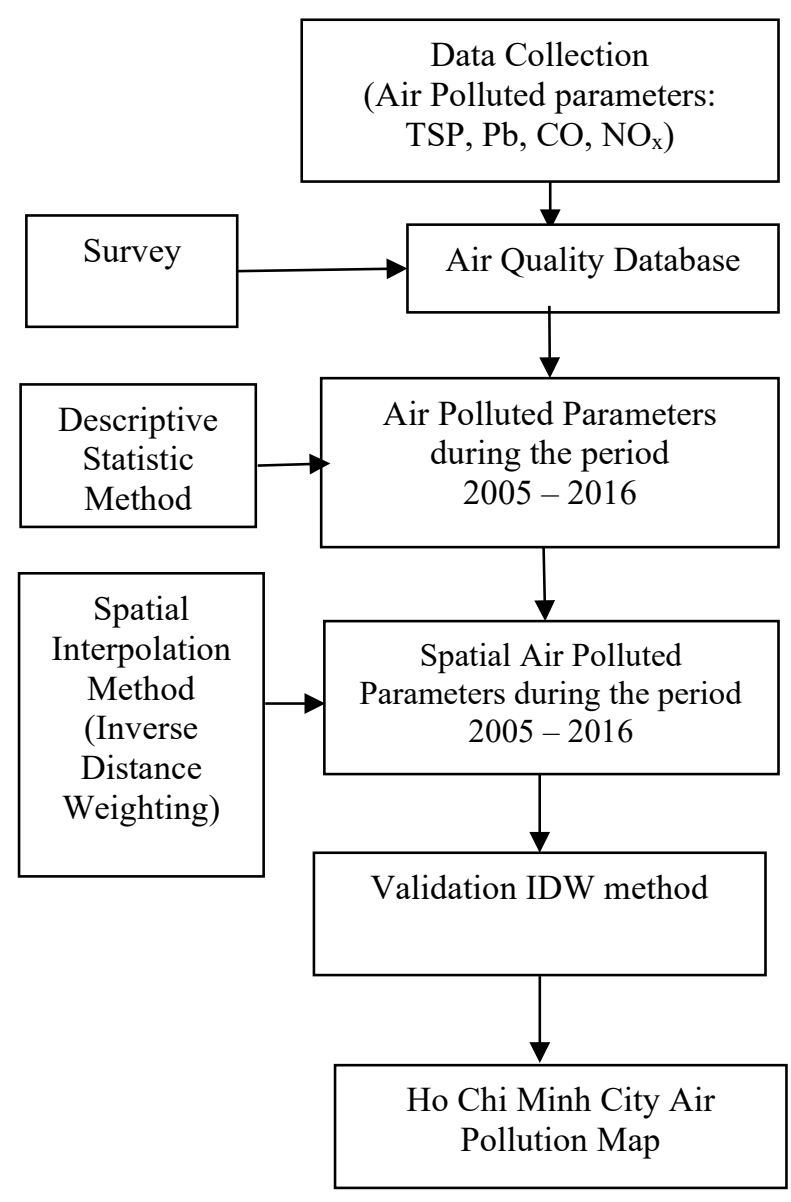
Figure 2. Schematic framework of research
methodology

\section{Spatial Interpolation Method}

Spatial Interpolation is a common method using for finding values of points in the researched areas without observing by collecting data based on data from observed points [10], [11], [12].. There are many different interpolation methods, namely IDW, Kriging, Spline. In this research, IDW method is chosen mainly because of its simplicity, fast, easy to use, and popular. Moreover, IDW can be best use if the density is large and distributed evenly in the researched area.

\section{Inverse Distance Weighting, IDW}

IDW is one of the most popular method to interpolate different points [13]. IDW method can determine the unknown points by calculating the average inverse distance weighting of the known points in the surrounding site by each pixel. Points that are far from unknown points have less influence in the calculated results, and nearby points have more influence in the inverse distance weighting. IDW is used to optimize the density of points. The nearer the points to the unknown points, the more influence they have on that point.

Pearson correlation coefficient $\left(R^{2}\right)$ an index of agreement (d)

The Pearson correlation coefficient $\left(\mathrm{R}^{2}\right)$ and an index of agreement (d) was applied to assess the IDW method [14] [15]. The $\mathrm{R}^{2}$ and $\mathrm{d}$ formula as below:

$$
R^{2}=\left[\frac{\sum_{i=1}^{n}\left(\mathrm{O}_{i}-\bar{O}\right)\left(P_{i}-\bar{P}\right)}{\sqrt{\sum_{i=1}^{n}\left(\mathrm{O}_{i}-\bar{O}\right)^{2}} \sqrt{\sum_{i=1}^{n}\left(P_{i}-\bar{P}\right)^{2}}}\right]^{2}
$$

where $O i$ is the observation value and $P i$ is the forecast/interpolation value and Obar is average of observation values and Pbar is average of forecast values.

$$
d=1-\frac{\sum_{i=1}^{n}\left(\mathrm{O}_{i}-P_{i}\right)^{2}}{\sum_{i=1}^{n}\left(\left|P_{i}-\bar{O}\right|+\left|O_{i}-\bar{O}\right|\right)^{2}}
$$

\section{Results and Discussions}

\subsection{Preliminary Interpretation}

It is necessary to perform an initial assessment of data before analyzing trends in spatiotemporal. The boxplots are applied to give an overall picture of Total Suspended Particles (TSP), Nitrogen Oxide $\left(\mathrm{NO}_{\mathrm{x}}\right)$, Lead $(\mathrm{Pb})$, etc. Figures 3, 4, 5, and 6 illustrate a considerable difference in the annual amount of $\mathrm{CO}, \mathrm{TSP}, \mathrm{NO}_{\mathrm{x}}$, and $\mathrm{Pb}$ at 15 monitoring locations for the study period.

The trend of Carbon monoxide (CO)

The $\mathrm{CO}$ concentration in every monitoring location in the period of 2015 - 2016 does not exceed the national limits of $\mathrm{CO}$ concentration (according to QCVN 05:2013/MONRE, the national limit of CO concentration for 1 hour is $30 \mathrm{mg} / \mathrm{m}^{3}$ ). However, compared to the national limit of CO concentration for 8 hours, which is $10 \mathrm{mg} / \mathrm{m}^{3}$, some monitoring locations such as Go Vap, Dinh Tien Hoang - Dien Bien Phu, An Suong, Hang Xanh, exceed the national limit. 


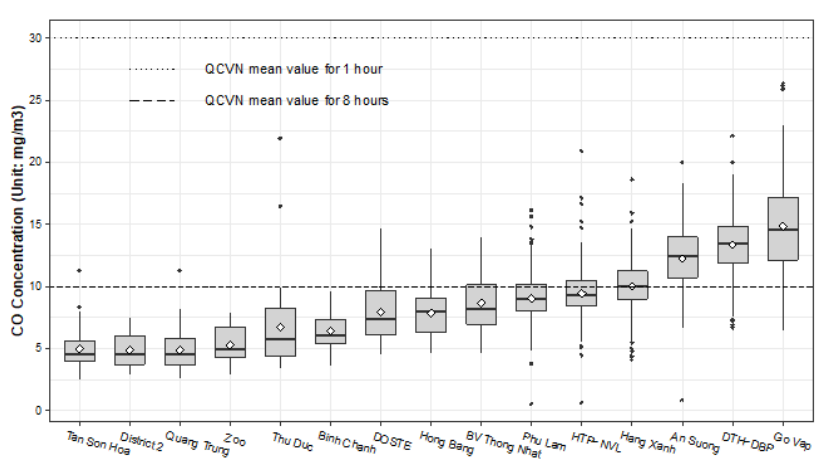

Figure 3. Temporal variations of $\mathrm{CO}$ at 15 stations. The inside diamonds stand for arithmetic means.

\section{Total Suspended Particles (TSP)}

TSP concentration in every monitoring location in the period of $2005-2016$ does exceed the national limit for TSP (according to QCVN 05:2013/MONRE, the national average TSP for the whole year is $0.1 \mathrm{mg} / \mathrm{m}^{3}$ ). For the national limit TSP for 24 hours, which is $0.2 \mathrm{mg} / \mathrm{m}^{3}$, only Tan Son Hoa, Quang Trung, Thu Duc, District 2, Zoo monitoring station does not exceed the national limit. For the national limit TSP for 1 hour, which is $0.3 \mathrm{mg} / \mathrm{m}^{3}$, An Suong, Huynh Tan Phat - Nguyen Van Linh, Dinh Tien Hoang - Dien Bien Phu, Phu Lam, Go Vap, Hang Xanh, Binh Chanh, Hong Bang, Thong Nhat, DOST monitoring stations are higher than that national limit.

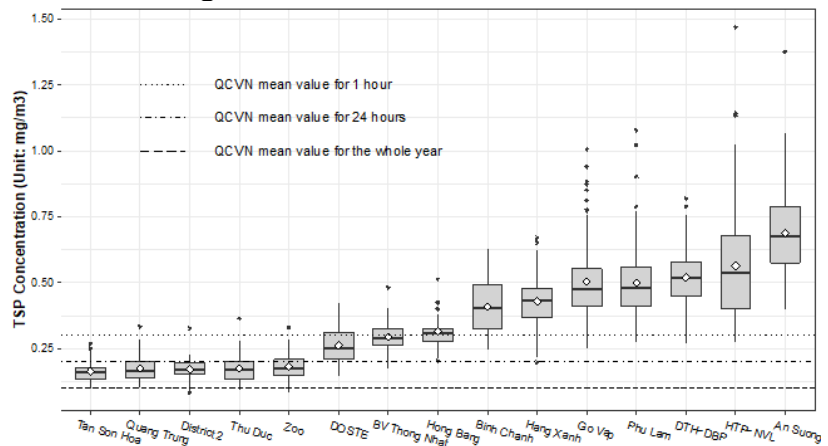

Figure 4. Temporal variations of TSP at 15 stations. The inside diamonds stand for arithmetic means.

\section{The trend of Lead $(\mathrm{Pb})$}

$\mathrm{Pb}$ concentration in every monitoring location in the period of 2005 - 2016 does not exceed the national limit for $\mathrm{Pb}$ (according to QCVN 05:2013/MONRE, the national limit of $\mathrm{Pb}$ for 24 hours is $1.5 \mu \mathrm{g} / \mathrm{m}^{3}$ ). Compared to the national limit of $\mathrm{Pb}$ concentration for the whole year, which is 0.5 $0.5 \mu \mathrm{g} / \mathrm{m}^{3}$, the $\mathrm{Pb}$ concentration in 6 monitoring locations in some moments, exceed the national limit.

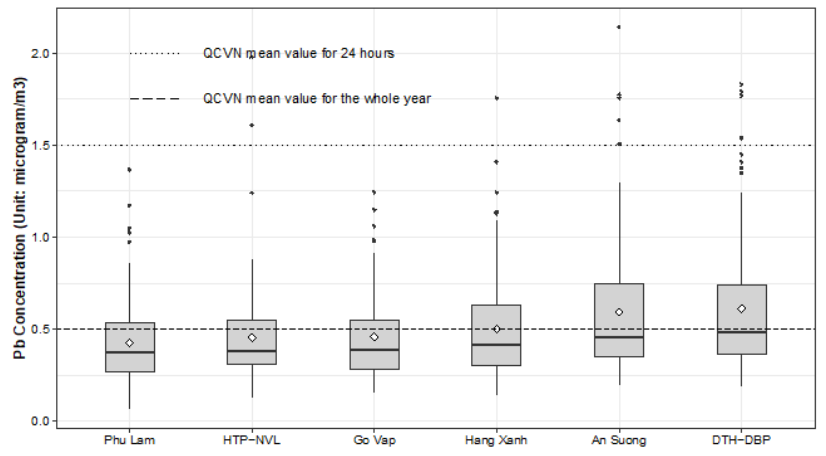

Figure 5. Temporal variations of annual $\mathrm{Pb}$ at 6 stations. The inside diamonds stand for arithmetic means.

In 1921, "Tetraethyl lead" was used to be added to gasoline to help reduce engine knocking, boost octane ratingsmixed for the internal combustion engine. But in 1975 the US requested the removal of "Tetraethyl lead" because it was toxic to human health. In Vietnam in 2001, the Prime Minister of Vietnam also issued a decision banning the use of "Tetraethyl lead" in gasoline. However, because of economy issue, some traders still secretly put "Tetraethyl lead" in gasoline. Therefore, $\mathrm{Pb}$ concentration is still found in Ho Chi Minh City air.

The trend of $\mathrm{NO}_{\mathrm{x}}$

In the period of $2005-2016$, compared to the national limit of $\mathrm{NO}_{\mathrm{x}}$ for 1 hour is $0.2 \mathrm{mg} / \mathrm{m}^{3}$ (as QCVN 05:2013/MONRE), the $\mathrm{NO}_{\mathrm{x}}$ concentration recorded in Dinh Tien Hoang - Dien Bien Phu exceeds the national limit. Compared to the $\mathrm{NO}_{\mathrm{x}}$ average for 24 hours, which is $0.1 \mathrm{mg} / \mathrm{m}^{3}$, Dinh Tien Hoang - Dien Bien Phu, An Suong, Go Vap, Hang Xanh, Huynh Tan Phat - Nguyen Van Linh, Phu Lam all exceeds the national limits.

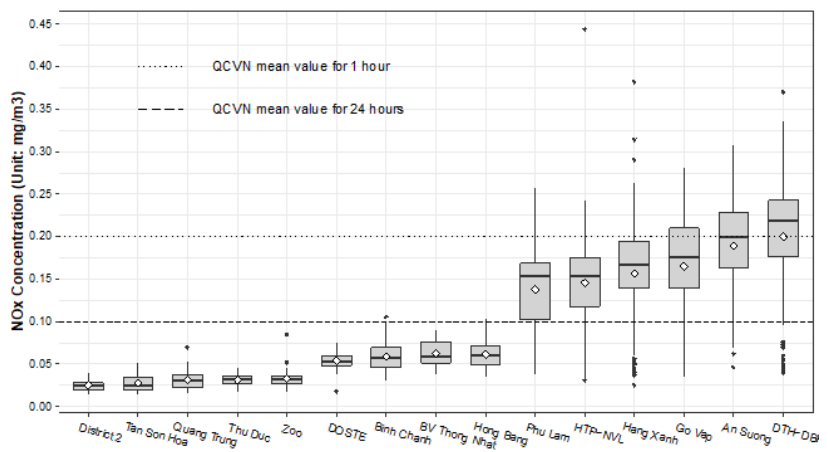

Figure 6. Temporal variations of annual $\mathrm{NO}_{x}$ at 15 stations. The inside diamonds stand for arithmetic means.

\subsection{Evaluation of accuracy of spatial interpolation method}


The data after processing is divided into 2 samples: testing sample and interpolation sample. The project divided the sample by a ratio of $2: 4$ (2 testing stations and 4 interpolation stations, 15 cases) and 3: 3 (3 testing stations and 3 interpolation stations, 20 cases). Data used for interpolation included $\mathrm{CO}$ and $\mathrm{NO}_{\mathrm{x}}$ parameters of 6 monitoring stations in the period of $2005-2016$.

The results illustrated that the IDW interpolation method which was used to calculate $\mathrm{CO}$ concentration is suitable with $\mathrm{R}^{2}=0.93$ and $\mathrm{d}=0.74$ at Dinh Tien Hoang Dien Bien Phu, An Suong and Go Vap monitoring locations. The IDW interpolation method was also good result for $\mathrm{NO}_{\mathrm{x}}$ with $\mathrm{R}^{2}=0.96$ and $\mathrm{d}=0.75$ at the Hang Xanh, An Suong, and Huynh Tan Phat monitoring locations.

From the results, it is clear that the IDW interpolation method is suitable in this research because results of methodology validation with $\mathrm{R}^{2}$ is higher than 0.6 [16]. In addition, for mapping the air quality over city has 3 main methods: (i) monitoring air quality by thousands stations over the city and intergrate with smart information technology infrastructure to collect and analysis monitored data, however this method is very expensive because each station range from 250,000 USD- 500,000 USD. Therefore, the developing city as HCMC doesn't have enough resources for air quality mapping by this method; (ii) air quality modeling, however this method needs many inputs for air quality model such as air emission inventories. However, in HCMC as developing city doesn't have system to collect energy consumption of each emitter, doesn't have online monitoring air pollution from each factory and don't have traffic model to collect online traffic flow; (iii) Mapping air quality over HCMC by using IDW interpolation method, this is cheapest and fastest method however this method has some uncertainty as mentioned above with $\mathrm{R}^{2}$ about 0.93 (noted that lowest uncertainty when $\mathrm{R}^{2}$ is 1.0).

With current situation as HCMC which is developing city, high air pollution level and high population (nearly 10 million official residents), they need air quality data over the city for developing good clean air action plan. Therefore, the results of this IDW method can help HCMC for these needs.

So the research used IDW method to implement spatiotemporal air polluted parameters and produce the map of air quality over Ho Chi Minh City.

\subsection{Spatial variability of air polluted factor in Ho Chi Minh city}

\section{Carbon oxit (CO)}

The main emission sources of $\mathrm{CO}$ are from burning gasoline fuel (motorcyles, cars) and coal in industry sector. In 2005, the Fig. 8 illustrates that the CO concentration level is highest in Dien Bien Phu location, and the spread continues towards northeast of the city center. In 2010, the CO concentration is high in Dien Bien Phu, Go Vap, and An Suong monitoring locations, and the spread continues towards the north and northwest of the city center. In 2015 , it is clear that the spread continues towards the northwest of the city center. This is because the main air emission sources is in center of HCMC and main wind direction of Ho Chi Minh City is southeast, south, and northeast. The wind direction blows air pollutants from center of city toward to the main ditrction of northwest of Ho Chi Minh City.
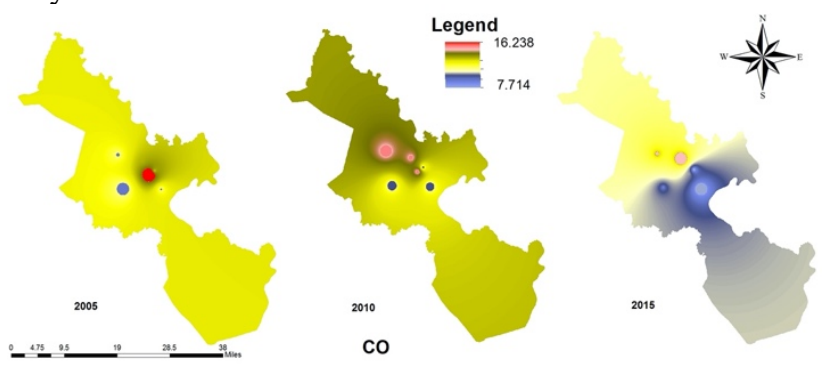
Figure 7. The map of illustrates the CO
concentration in 2005, 2010, and 2015

The change in $\mathrm{CO}$ concentration in the five - year period $2005-2010$ is $(-) 1,77-(+) 4,34 \mathrm{mg} / \mathrm{m} 3$ has the tendency to increase in the northwest of the city center. From 2010 to 2015 the $\mathrm{CO}$ concentration decreased dramatically; in all monitoring locations, the $\mathrm{CO}$ concentration did not exceed the national limie (according to QCVN 05:2013/BTNMT, the average $\mathrm{CO}$ concentration for 1 hour is $30 \mathrm{mg} / \mathrm{m} 3)$. The increasing of CO from 2005 to 2010 has two main reasons: (i) this period, the city had a lot of construction activities such as build houses, apartments, roads...; (ii) And road transportation vehicles were outdated technology/dirty vehicles (motocyles, cars, heavy trucks, light trucks, buses) with very low emission standards with EURO II emission standards [16].

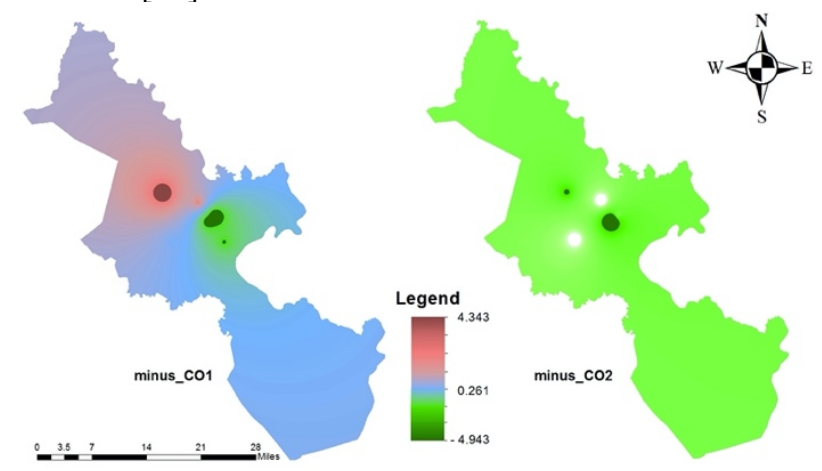

Figure 8. The illustrate the change in $\mathrm{CO}$ concentration in 5 - year periods: $2005-2010$ and $2010-2015$.

\section{Total Suspended Particles, TSP}

The main emission sources of TSP are from road transportation and construction.

In 2005, the graph in Figure 9 shows that the TSP is highest in An Suong, and the spread continues towards the 
north of the city center. In 2010, the TSP concentration in An Suong is still really high, and the spread continues towards the northwest of the city center. In 2010, the spread still continues towards the northwest of the city center. This is because the main air emission sources is in center of HCMC and main wind direction of Ho Chi Minh City is southeast, south, and northeast. The wind direction blows air pollutants from center of city toward to the main direction of northwest of Ho Chi Minh City.

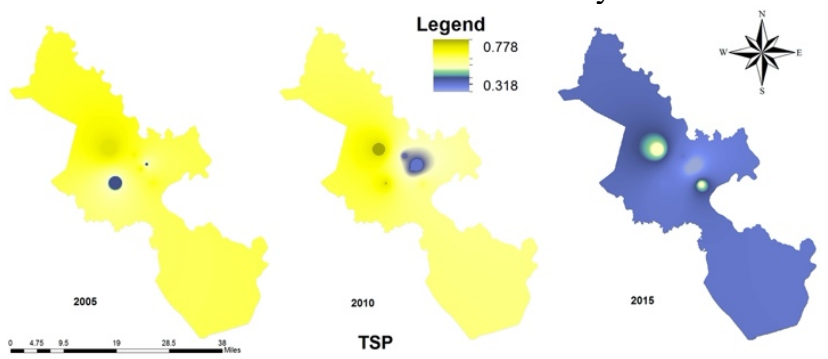

Figure 9. The map of illustrate the pollution by Total Suspended Particles in 2005, 2010, and 2015.

The TSP pollution in $2005-2010$ increases towards the west of the city center; period from $2010-2015$, it has the tendency to decrease $0,06-0,22 \mathrm{mg} / \mathrm{m}^{3}$. The TSP concentration in every monitoring location exceeds the national limit (according to QCVN 05:2013/MONRE, the average TSP allowed for 1 hour is $0,3 \mathrm{mg} / \mathrm{m}^{3}$ ). In 2015, the TSP concentration decreases significantly compared to other years and below the national limit of TSP concentrations. The increasing of TSP from 2005 to 2010 has two main reasons: (i) this period, the city had a lot of construction activities such as build houses, apartments, roads...; (ii) And road transportation vehicles were outdated technology/dirty vehicles (motocyles, cars, heavy trucks, light trucks, buses) with very low emission standards with EURO II emission standards [16]. But after 2010 TSP decreasing because Vietnam government released the new standard for exhaust air emission from road transportation vehicles more strictly and new regulation about cleaner fuel. In addition, after 2015, the contruction activities was reducing $[17,18]$.

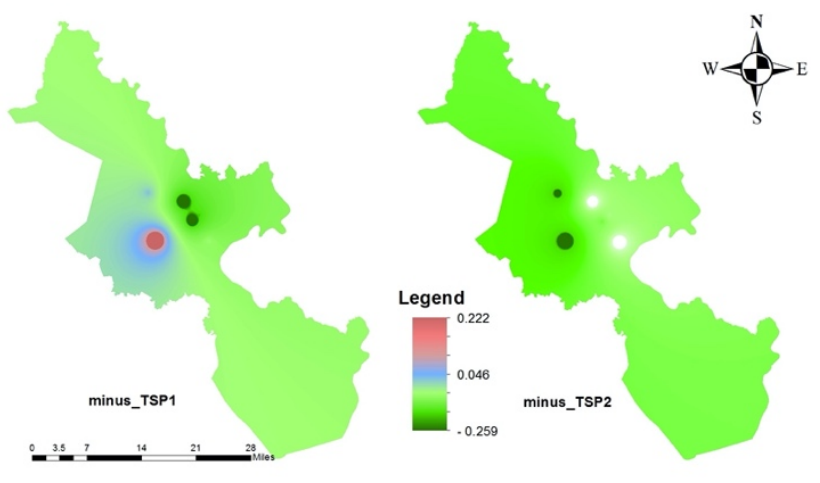

Figure 10. The map of illustrate the change in TSP concentration in the two five - year periods: 2005 2010 and $2010-2015$.

\section{$\mathrm{Pb}$}

The main emission sources of $\mathrm{Pb}$ in HCMC are from gasoline, diesel fuels (motorcyles, cars, trucks and buses) [19]. The Fig. 11 shows that the $\mathrm{Pb}$ spreads and towards the northwest of the city center, which is the highest recorded in An Suong. In 2010, the Pb concentration is really high in Go Vap, Dien Bien Phu monitoring locations, and the spread continues towards the northeast of the city center till 2013. However, the $\mathrm{Pb}$ concentration which is recorded from all monitoring locations does not exceed the average national limit (according to QCVN 05:2013/BTNMT, the average $\mathrm{Pb}$ concentration for 24 hours is $1.5 \mu \mathrm{g} / \mathrm{m}^{3)}$. The $\mathrm{Pb}$ concentration has the tendency to decrease; in the period from 2005 to 2010 , it decreases $0,05-0,41 \mu \mathrm{g} / \mathrm{m}^{3}$. From 2010 to 2013, the $\mathrm{Pb}$ concentration continues its trend, decrease $0,03-0,21 \mu \mathrm{g} / \mathrm{m}^{3}$ (Fig. 12)

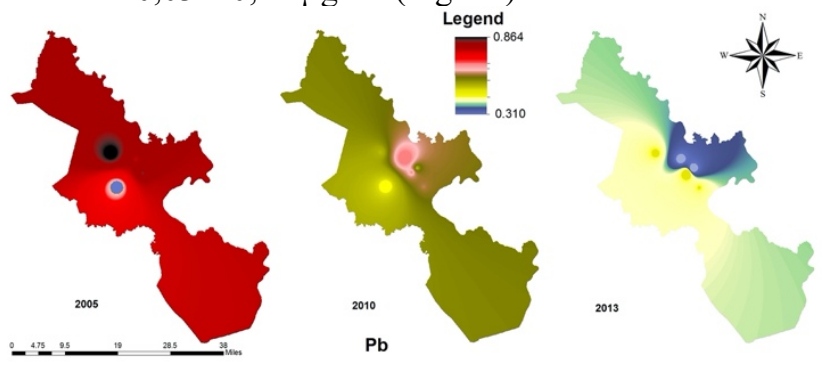

Figure 11. The map of illustrate the pollution of $\mathrm{Pb}$ in 2005, 2010, and 2013.

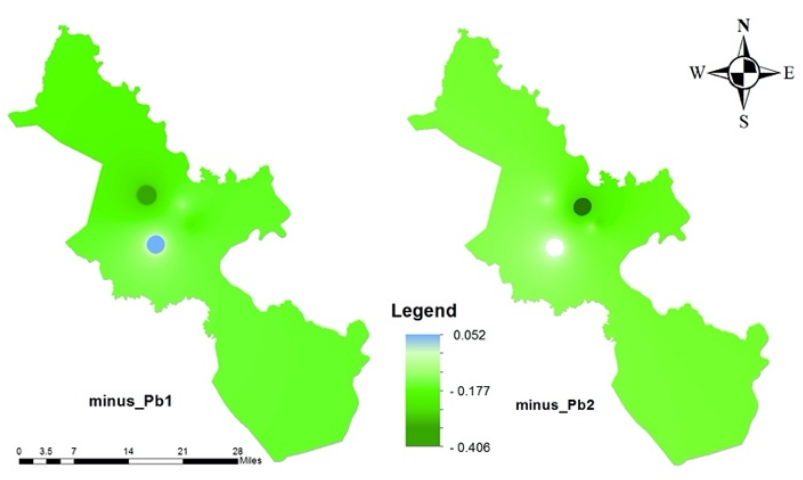

Figure 12. The map of illustrate the shift in $\mathrm{Pb}$ concentration in two periods: $2005-2010$ and 2010 $-2013$.

NOx

The main emission sources of NOx are from burning diesel fuel (trucks and buses, ship) and coal burning in industry sector [17]. 
In 2005, the $\mathrm{NO}_{\mathrm{x}}$ concentration focuses mainly in Hang Xanh and Dien Bien Phu monitoring locations, and the spread continues towards northeast of the city center. It is also clear that the NOx concentration in this trend exceeds the average national limit.
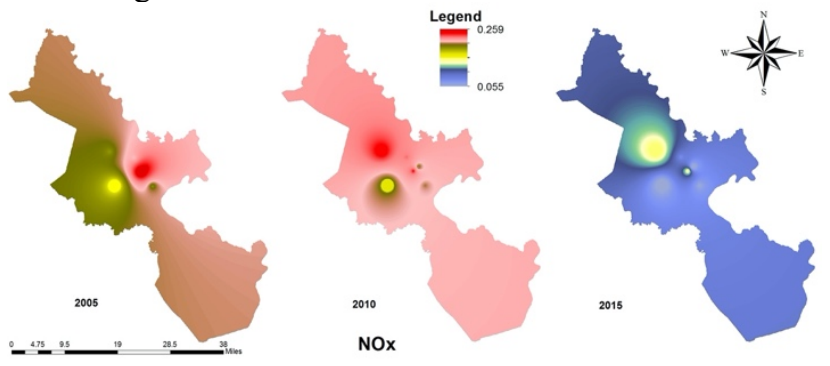

Figure 13. The map of illustrate the pollution of $\mathrm{NO}_{\mathrm{x}}$ in 2005, 2010, and 2015.

The Fig 13 shows that the $\mathrm{NO}_{\mathrm{x}}$ pollution increases towards the west of the city center in the period $2005-$ 2010. The Fig. 14 shows that from 2010 to 2015 , the $\mathrm{NO}_{\mathrm{x}}$ pollution has the tendency to decrease from $0,102-0,141$ $\mathrm{mg} / \mathrm{m}^{3}$. The concentration of NOx deceased from 20102015 because before 2010 road transportation vehicles were outdated technology/dirty vehicles (motocyles, cars, heavy trucks, light trucks, buses). But after 2010, Vietnam government released the new standard for exhaust air emission from road transportation vehicles more strictly and new regulation about cleaner fuel [18].

In 2010 , the $\mathrm{NO}_{\mathrm{x}}$ pollution continues towards to the north of the city center and also exceeds the national limit of $\mathrm{NO}_{\mathrm{x}}$. As mentioned above is that the main air emission sources is in center of HCMC and main wind direction of Ho Chi Minh City is southeast, south, and northeast. The wind direction blows air pollutants from center of city toward to the main ditrction of north of Ho Chi Minh City.

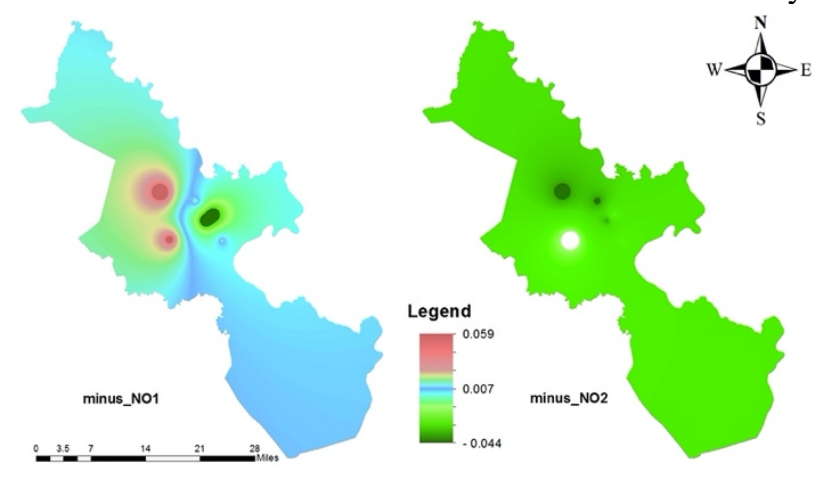

Figure 14. The map of illustrates the change in $\mathrm{NO}_{x}$ in two five - year periods: 2005 - 2010 and 2010 2015.

\section{Conclusions}

In this paper, the spatial and temporal patterns of Carbon monoxide (CO), Total Suspended Particles (TSP), Nitrogen oxide $\left(\mathrm{NO}_{\mathrm{x}}\right)$, lead $(\mathrm{Pb})$ time series at 15 stations in HCMC were examined by using the notched boxplot. Another remarkable finding is that the concentration of TSP at monitoring stations in the period of 2005 - 2016 exceeded the Vietnam national technical regulation for ambient air (under Ministry of Environment and Natural Resources, Vietnam standard) for TSP concentration in ambient air (average annual TSP concentration was $0.1 \mathrm{mg}$ $/ \mathrm{m}^{3}$ according to QCVN. The results of study also shown that relation between policy and air pollution level. Policy interventions on air quality management will have a major impact on reducing air pollution for HCMC, such as policies that tighten vehicle exhaust emissions (from EURO II standard to EURO VI standard) and policy on cleaner fuel.

In general, this study shows an overall picture of longterm the air polluted variability in terms of space and time, which makes it possible for further investigations deeply to evaluate the relationship between climatic parameters and environmental quality. In addition, these detailed results are useful to address the air quality risks in HCMC.

\section{References}

[1] H. C. M. C. S. Office., Statistic Year Book of 2018, Ho Chi Minh, 2018.

[2] V. HEPA (Ho Chi Minh environmental protection agency. Ho Chi Minh city, "Report 2010 air quality in HCMC, Ho Chi Minh city, Vietnam," Ho Chi Minh, 2010.

[3] HEI, "Effects of Short-Term Exposure to Air Pollution on Hospital Admissions of Young Children for Acute Lower Respiratory Infections in Ho Chi Minh City, Vietnam.," Ho Chi Minh, 2012.

[4] WEF, "Air pollution threatens national health. Davos, Switzerland: World Economic Forum," Ho Chi Minh, 2012.

[5] F. G. Bang Q. Ho. Clappier A, "Air pollution forecast for Ho Chi Minh City, Vietnam in 2015 and 2020.," Air Qual. Atmos. Health, vol. 4, pp. 145-58., 2011.

[6] W. H. O. (WHO), "IARC: Diesel engine exhaust carcinogenic.," Ho Chi Minh, 2012.

[7] L. D. G. N. I. Giang, "Air Pollution Blamed as Study Finds Respiratory Illness Hitting HCMC's Children.," 2008.

[8] A. D. Bank, "Ho Chi Minh City Adaptation to Climate Change, Summary Report," Mandaluyong City, Philippines., 2010.

[9] M. L. \&. M. H., Spatial Interpolation. Geographical information systems: principles, techniques, management and applications, 1, 481-492., 1999. 
[10] P. Burrough, Principles of Geographical Information Systems for Land Resources Assessment, Oxford University Press, Oxford, 1986.

[11] M. MacCullagh, "Terrain and surface modelling systems: theory and practice," Photogrammetric Record, , Vols. 12, , no. 72, pp. 747-779, 1988.

[12] G. Robinson, "The accuracy of digital elevation models derived from digitised contour data.," Photogrammetric Record, vol. 14, no. 83, p. 805814, 1994.

[13] G. Schut, "Review of interpolation methods for digital terrain modelling," in XIIIth Congress of International Society for Photogrammetry, Helsinki, Commission III, Helsinki, 1976.

[14] K. P. a. F. W.A., "Integrated research on the hydrological process dynamics from the Wilde Gera catchment in Germany," in Headwater Control VI: Hydrology, Ecology and Water Resources in Headwaters, IAHS Conference, Bergen, 2005.

[15] W. C.J., "On the evaluation of model performance in physical geography," in Spatial Statistics and Models, edited by: Gaile G.L. and Willmot C.J., D. Reidel, Dordrecht, 1984, p. pp. 443-460.

[16] Bang Q. Ho, "Optimal Methodology to Generate Road Traffic Emissions for Air Quality Modeling Application to Ho Chi Minh City", 2010.

DOI: 10.5075/epfl-thesis-4793. EPFL_TH4793. PhD Thesis, 190 pages.

https://infoscience.epfl.ch/record/149809?ln=fr

[17] Bang Q. Ho., Khue H.N. Vu, Tam T.Nguyen, Hang T.T. Nguyen, Thuy T.T. Nguyen. 2019. A combination of bottom-up and top-down approaches for calculating of air emission for developing countries: A case of Ho Chi Minh city, Vietnam. Air Quality, Atmosphere \& Health J. DOI: 10.1007/s11869-019-00722-8.

[18] MOST (Ministry of Sciences and Technology), "National technical regulation on gasoline, diesel fuel oils and biofuels. QCVN 1 : 2009/BKHCN" 2009.

[19] HEPA (Ho Chi Minh City Environmental Protection Agency), "Report on the current state of the environment in Ho Chi Minh City for period 5 years of 2005-2010", 2011. Technical report. 210 pages. 